\title{
Experimental Analysis on Solid Desiccant Used in An Air Conditioning
}

\author{
Ekadewi Anggraini Handoyo ${ }^{1,{ }^{*}}$, Andriono Slamet ${ }^{1}$, and Muhammad Danang Birowosuto ${ }^{2}$ \\ ${ }^{1}$ Mechanical Engineering Department, Petra Christian University, J1. Siwalankerto No.121-131, \\ Surabaya 60236, Indonesia. \\ ${ }^{2}$ CNRS International NTU Thales Research Alliance (CINTRA), Research Techno Plaza, 50 Nanyang \\ Drive, Border X Block, 637553, Singapore
}

\begin{abstract}
Garden by The Bay in Singapore is the world's largest coolest conservatories. Although it is located in tropics and uses so many glasses, its electricity consumption is as much as a commercial building. The key to this low consumption is in air cooling technology. Air used for cooling the conservatories is dehumidified first using liquid desiccants before cooled. The same technology was implemented to a single-split air conditioner (AC) that works on a vapor-compression refrigeration cycle. The experiments were conducted in a room with opened and closed door. Instead of using a liquid desiccant, the experiment used a solid desiccant, i.e., silica gel which thickness was $6 \mathrm{~mm}$ and $8 \mathrm{~mm}$ with density equals to $1.27 \mathrm{gr} \mathrm{cm}^{-3}$. From the experiment, it is found that: (i) the thicker the silica gel, the higher outlet air temperature from silica gel, (ii) less condensate will be produced when the silica gel used is thicker, (iii) silica gel is suitable for reducing humidity of outdoor/fresh air, and (iv) the electricity consumption saving for inserting $8 \mathrm{~mm}$ silica gel is only $4 \%$ when the door is closed and $31 \%$ when the door is opened.
\end{abstract}

Key words: Dehumidification, electricity saving evaporator, relative humidity, silica gel.

\section{Introduction}

As a country located in tropics, the weather in Indonesia is humid and hot. Global warming makes it worse. Nowadays, air conditioning is required in almost all building and houses in densely populated cities in Indonesia. A principal purpose of the air conditioning system is to provide conditions for human thermal comfort. "Thermal comfort is that condition of mind that expresses satisfaction with the thermal environment." In general, comfort occurs when the air temperature is maintained at $22{ }^{\circ} \mathrm{C}$ to $26{ }^{\circ} \mathrm{C}$, and its relative humidity (RH) is lower than $60 \%$ [1]. This comfort condition was available a long time ago, but it is not anymore now. For example, the air temperature and RH in Surabaya, Indonesia could reach $75^{\circ} \mathrm{F}$ to $93{ }^{\circ} \mathrm{F}\left(24{ }^{\circ} \mathrm{C}\right.$ to $\left.34{ }^{\circ} \mathrm{C}\right)$ and $4 \%$ to $96 \%$, respectively [2]. Since this condition can not meet the comfort criteria, air conditioning is required.

\footnotetext{
* Corresponding author: ekadewi@petra.ac.id
} 
Another country in tropics has the same climate that is Singapore. One well-known icon of the city available since 2012 is Garden by The Bay. These Singapore superstructures are the world's largest coolest conservatories. These conservatories are Flower Dome and Cloud Forest. Building two cooled conservatories in a place that is so close to the equator and where fuel resources are limited was considered madness [3]. Yet, its electrical consumption is not more than a modern office building in Singapore. Air used for cooling is dehumidified first using liquid desiccants. Then, this less moisture air is cooled with chilled water. The desiccants are regenerated using a combination of waste heat from a biomass system and solar energy [4].

An air-conditioning system with a silica gel bed was evaluated in an experimental investigation in India. From the experiment, it was found that the electricity saving was about $19 \%$ [5]. The combined liquid desiccant dehumidification and vapor compression system, defined as hybrid liquid desiccant systems, was studied extensively to improve the performance of these systems. Different configurations of hybrid liquid desiccant systems and their components were investigated [6]. The use of solar energy to drive airconditioning is attractive since the cooling load has a high coincidence with the availability of solar irradiation. A simulation with Mediterranean Region data was conducted to compare a solar desiccant solid system (DEC), absorption refrigerant chillers, and a conventional vapor compression refrigerator. It is found out that the DEC system can achieve a primary energy saving of around $40 \%$, compared to an absorption refrigerant and of around $150 \%$ compared to a conventional vapor compressor refrigerator [7]. Performance study of solid desiccant vapor compression hybrid air-conditioning system has been experimentally carried out for typical hot and humid weather of Roorkee. The present system has ensured a $61.7 \%$ reduction in process air humidity ratio at the outlet of the desiccant wheel as compared to outdoor humidity ratio [8]. A two-dimensional heat and mass transfer theoretical model of cross-flow dehumidifier for household split air conditioner have been established [9].

A simulation with TRNSYS model was conducted to investigate the feasibility of using a desiccant cooling system combined with the heat wheel and heat source as an alternative HVAC in buildings. An experimental study has been performed at Tohoku University in Japan to compare the model. The results show that such a system is feasible for cooling building in hot-humid climates, especially when solar energy is used to regenerate the desiccant wheel [10]. A desiccant air-conditioning (DAC) can be operated by solar thermal energy for moderate humid climates. The performance of the DAC system improves with higher regeneration temperature until its threshold. This threshold regeneration temperature depends on several parameters such as the desiccant material, its flow rate, and air velocity. A multi-stage DAC system can be operated at lower regeneration temperature as compare to single-stage cycle with the same dehumidification amount [11]. Rotary DAC system combines desiccant dehumidification and evaporative cooling. This air conditioning system is advantageous because it is free from CFCs refrigerant and able to use low-grade heat source (such as solar energy and waste heat). Compared with conventional vapor compression air conditioning system, it gives the advantage of environment-friendly, energy saving, healthy, comfortable [12].

Liquid desiccant was successfully used in a central air conditioning system in Garden by The Bay. Many researchers also reported that the desiccant could be used in air conditioning [5-10]. Some experiment was conducted to know the effect of solid desiccant, which is silica gel, on a small air conditioning. Almost all of the previous research was conducted with an evaporative cooler with silica gel. In this research, the solid desiccant, i.e., silica gel will be used with a vapor-compression refrigeration or single-split air conditioner (AC) system. The electric consumption and process of air flowing thru silica gel and air conditioner will be analyzed. 


\section{Method}

The solid desiccant, silica gel, was installed above the return grille of the single-split AC. The air will be drawn by the fan to flow thru silica gel first before being cooled with evaporator pipe of the AC. The schema of the experiment apparatus and the position of the measurement device is shown in Figure 1. While the equipment used is shown in Figure 2.

Figure 1 shows the measurement of air temperature include dry bulb - DB and web bulb - WB. It was measured at the supply of AC, return of AC, and after silica gel before being cooled. Six thermocouples type K was used with a KRN100 logger to record the air temperature. The air flow is measured using digital anemometer, which accuracy is $\pm 0.1 \mathrm{~m} \mathrm{~s}^{-1}$. The wood box in Fig. 2 was used as a channel of the air flow thru silica gel. The thickness of silica gel bed used was $6 \mathrm{~mm}$ and $8 \mathrm{~mm}$ with density $1.27 \mathrm{gr} \mathrm{cm}^{-3}$.

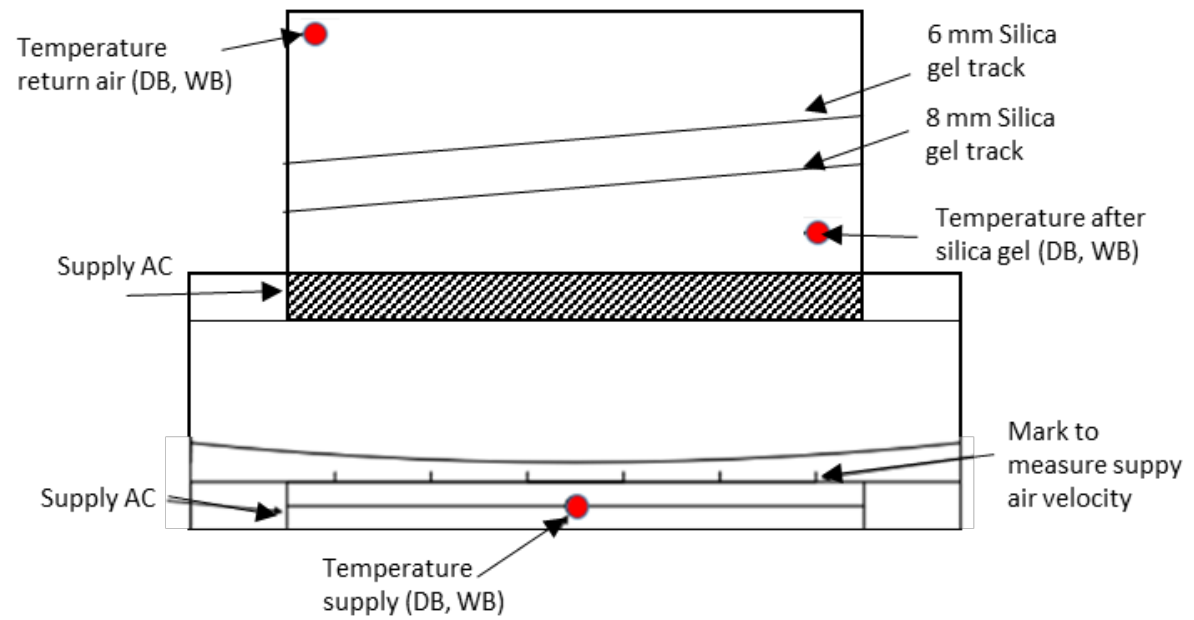

Fig. 1. Schema of experiment apparatus and position of the measurement device.

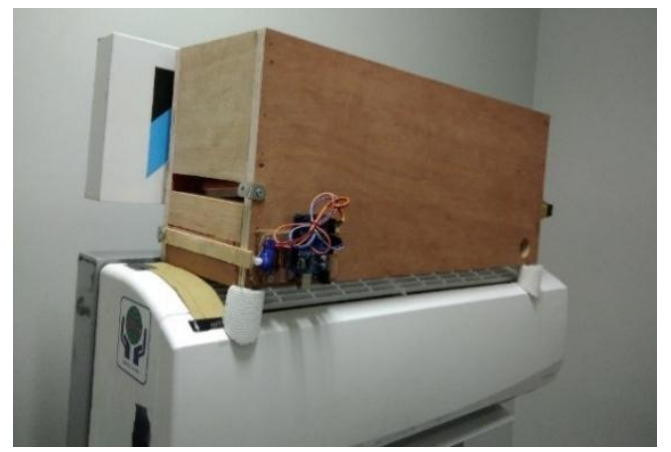

Fig. 2. A device used in the experiment of this research

The water condensate resulted in the $\mathrm{AC}$ was measured during the experiment to be used to analyze the air humidity as a result of silica gel usage. A digital $\mathrm{kWh}$-meter was also installed to obtain electric consumption of the AC.

First, the experiment was conducted only on the single-split AC with no silica gel. Then, silica gel was inserted before air flow enter the AC with a thickness of $6 \mathrm{~mm}$ and $8 \mathrm{~mm}$. So, there were three sets of an experiment conducted. This experiment was 
conducted with the door closed or air circulated inside the testing room. To investigate the effect of using silica gel in AC when outdoor or fresh air was used, the experiment was repeated with the door opened.

\section{Result and discussion}

The temperature of supply and return air of the AC with and without silica gel are shown in Figure 3 (a) and Figure 3 (b) for door closed and opened, respectively. The temperature of the air after passed thru silica gel (SG) are also shown in Figure 3 (a) and Figure 3 (b) as SG DB.

Figure 3 (a) and Figure 3 (b) show that the air temperature increased as it passed thru the silica gel either $6 \mathrm{~mm}$ or $8 \mathrm{~mm}$ thickness. During closed-door experiment without silica gel, the supply air could be as low as $10.45{ }^{\circ} \mathrm{C}$ while the return air was $20.95{ }^{\circ} \mathrm{C}$ at the steady condition. Silica gel in $6 \mathrm{~mm}$ decreased the air flow and made the room or return air was higher slightly, i.e. $23.25^{\circ} \mathrm{C}$. Flowing thru silica gel, the air temperature increased to be $24.15{ }^{\circ} \mathrm{C}$. Being cooled in evaporator, its temperature reached $9.95{ }^{\circ} \mathrm{C}$. For an $8 \mathrm{~mm}$ silica gel, return air was $24.25^{\circ} \mathrm{C}$ and after silica gel reached $26.05^{\circ} \mathrm{C}$. Being cooled, the supply air was $10.8{ }^{\circ} \mathrm{C}$. Thus, the air temperature difference between in and out was $10.5^{\circ} \mathrm{C}$ for air flow without silica gel, and $13.3{ }^{\circ} \mathrm{C}$ and $13.45^{\circ} \mathrm{C}$ for $6 \mathrm{~mm}$ and $8 \mathrm{~mm}$ silica gel bed. The thicker the silica gel, the higher the outlet air temperature from silica gel. This condition were found whether the door closed or opened. This happens because silica gel works by adsorption process.

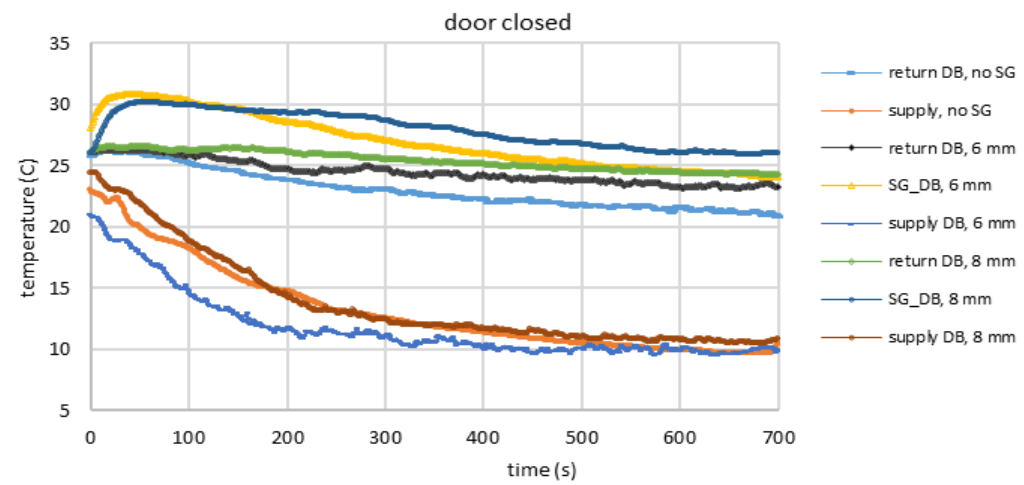

(a) Experiment with the door closed

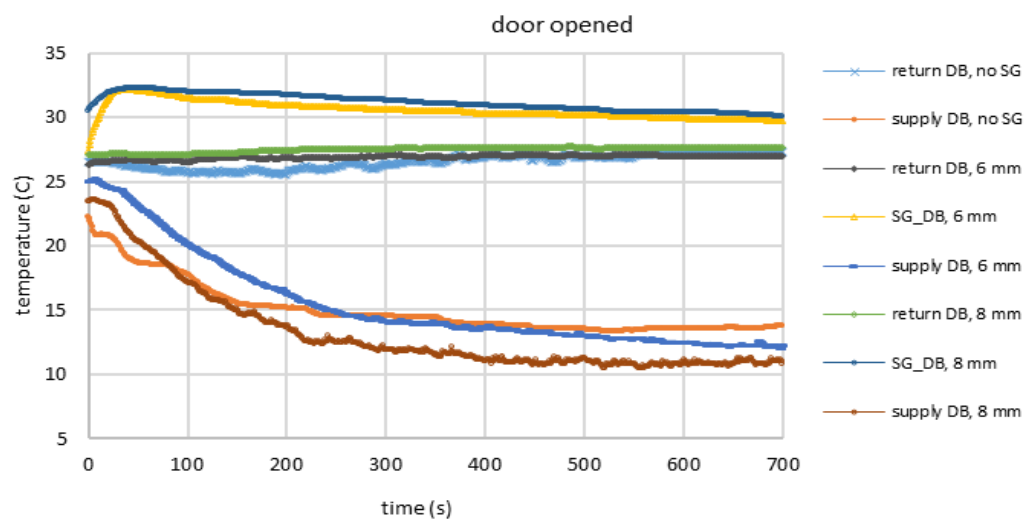

(b) Experiment with the door opened

Fig. 3. Temperature measured during the experiment 
The water in the air will be absorbed by the silica gel as it passes thru them. This adsorption process is exothermic and makes air temperature increases. The air humidity becomes less. This adsorption process experienced by the air is shown in Figure 4. Data in Figure 4 was an example for air passed thru (i) $8 \mathrm{~mm}$ silica gel when the door closed and (ii) $6 \mathrm{~mm}$ silica gel when the door opened. The same trend will happen for other condition.

The humidity ratio of the "return air" will decrease when it passes thru the silica gel and its dry-bulb temperature increase. Then, this "after-SG air" will flow thru the cooling coil of the evaporator. It is cooled and becomes "supply air." The cooling process of the after-SG air to supply air will produce less dew or condensate compare to the cooling process from the return air to supply air. When the door is opened during the experiment, the humidity of the return air is higher than when the door is closed. The cooling coil works harder in Figure 4 (b) than Figure 4 (a). The condensate produced by cooling coil during the experiment, i.e., two hours is shown in Figure 5. When the door is opened, humid air enters the cooling coil and produce more condensate than when it is closed. Silica gel reduces the condensate because some of water vapor in the air is already absorbed before reach the cooling coil. Less condensate produced when the silica gel used is thicker, i.e. $8 \mathrm{~mm}$. Thick silica gel means more silica gel that can absorb more water vapor.

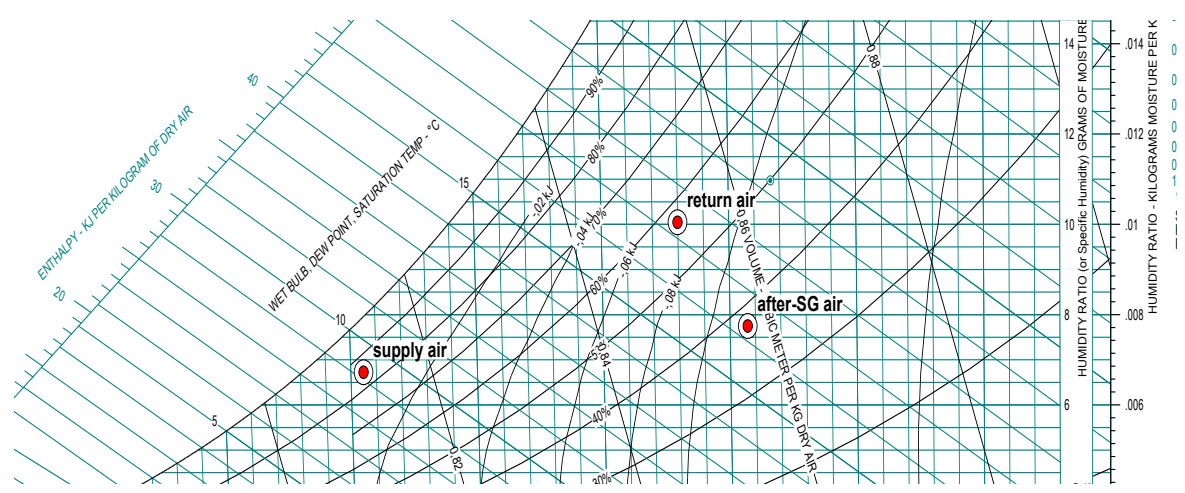

(a) 8-mm silica gel when the door closed

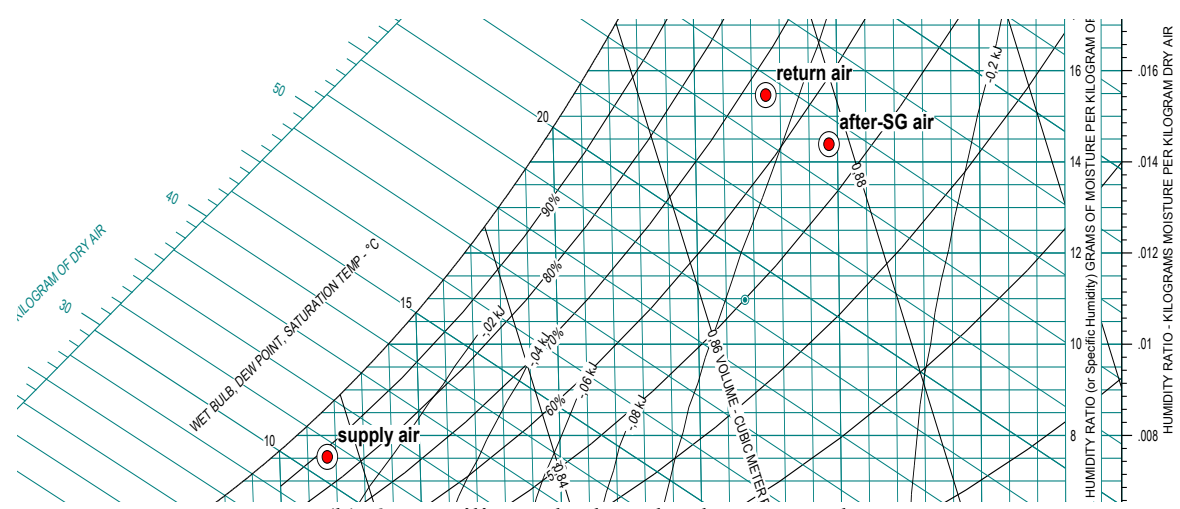

(b) 6-mm silica gel when the door opened

Fig. 4. The state of the air flowing in $\mathrm{AC}$ with silica gel 


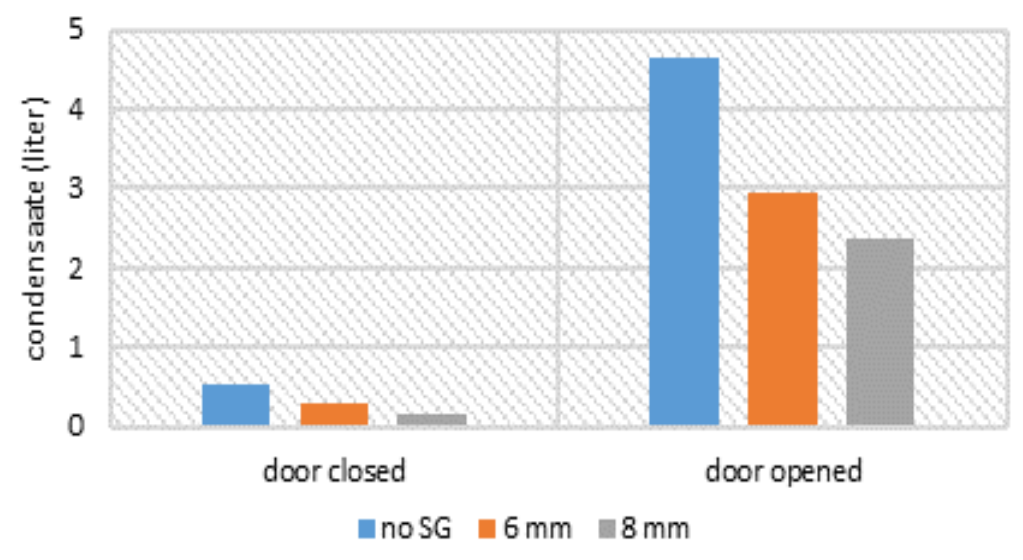

Fig. 5. The condensate produced by cooling coil of the evaporator of the AC for $2 \mathrm{~h}$ experiment

Figure 6 (a) and Figure 6 (b) show the room dry-bulb temperature and its relative humidity (RH) when it returns to the AC from the room for door closed and opened, respectively. When the door was closed, the room temperature reached lowest when no silica gel used and the highest when 8-mm silica gel inserted in the AC. Opposite to that, room RH was the lowest when 8 -mm silica gel used. Figure 5 shows that the condensate produced when 8-mm silica gel used is the least. Silica gel used in this experiment had good performance, i.e., dry air, less condensate but higher air temperature. The same phenomenon also happened when the door was opened. The air temperature was the lowest when no silica gel used, and RH was the lowest when $8-\mathrm{mm}$ silica gel used before the cooling coil.

The room conditions could be very different if the door is opened or closed. From Figure 6 (a), the room DB temperature and relative humidity could be $21.0{ }^{\circ} \mathrm{C}$ and $69 \%$, respectively, when the door was closed and no silica gel used. From Figure 6 (b), it could be $27.4{ }^{\circ} \mathrm{C}$ and $67.5 \% \mathrm{RH}$. The room DB temperature increased around $30 \%$ because of opening the door when no silica gel. When silica gel used, the room DB increased $16 \%$ and $14 \%$ for the thickness of $6 \mathrm{~mm}$ and $8 \mathrm{~mm}$, respectively. Room DB temperature in Figure 6 (b) looks to change rapidly. It is because outdoor air affects the room temperature. Opening the door could be considered equal to letting some fresh or outdoor air entering the room.

From Figure 6, it is found that silica gel affected the room temperature when the door was closed but did not affect when the door was opened. The room temperature at steady condition changed $10.7 \%$ and $14.5 \%$ when 6-mm silica gel and 8-mm silica gel used, respectively. While for opened-door condition, the room temperature changes only $1.2 \%$ and $1.1 \%$ for having $6 \mathrm{~mm}$ and $8 \mathrm{~mm}$ silica gel. 
Experiment with door closed
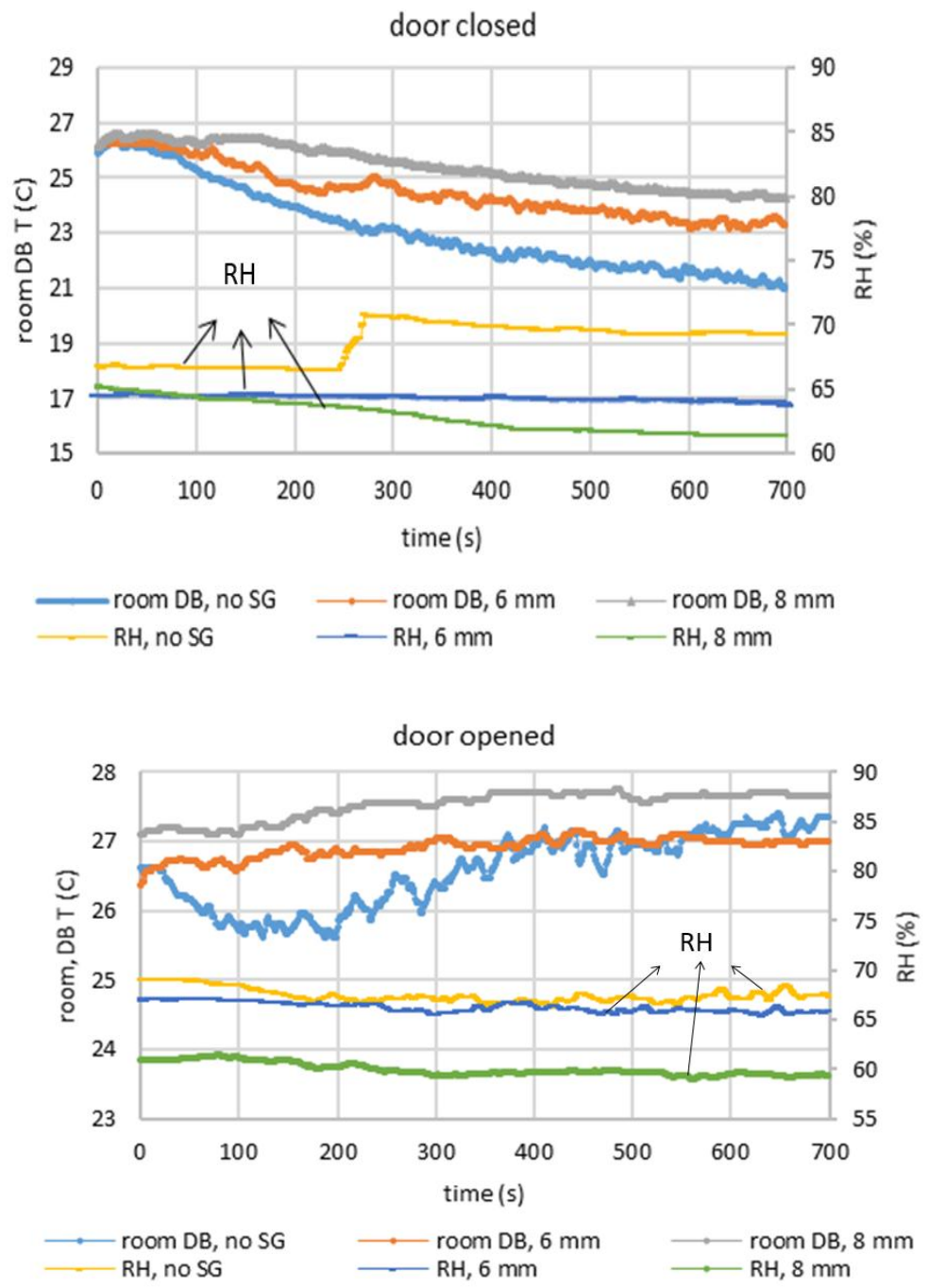

(a) Experiment with the door opened

Fig. 6. Comparison of room temperature when the $\mathrm{AC}$ with and without silica gel

Though silica gel has a lot of benefit, it has some disadvantage, too. Silica gel is easy to find and economically friendly. It is only IDR $45000 \mathrm{~kg}^{-1}$ with density around $700 \mathrm{~kg} \mathrm{~m}^{-3}$. The silica gel absorbs the water vapor in the air coming to the AC. The air flow rate decreases because the silica gel makes high-pressure drop, as shown in Figure 7. The room DB temperature reduced much quickly when no silica gel used, as shown in Figure 6 (a). The low air flow rate produced by $\mathrm{AC}$ makes the room temperature decreasing very slowly. It is a disadvantage of adding silica gel. Yet, the air relative humidity is lower when the silica gel used is thicker. So, there is an advantage and disadvantage of adding silica gel. 


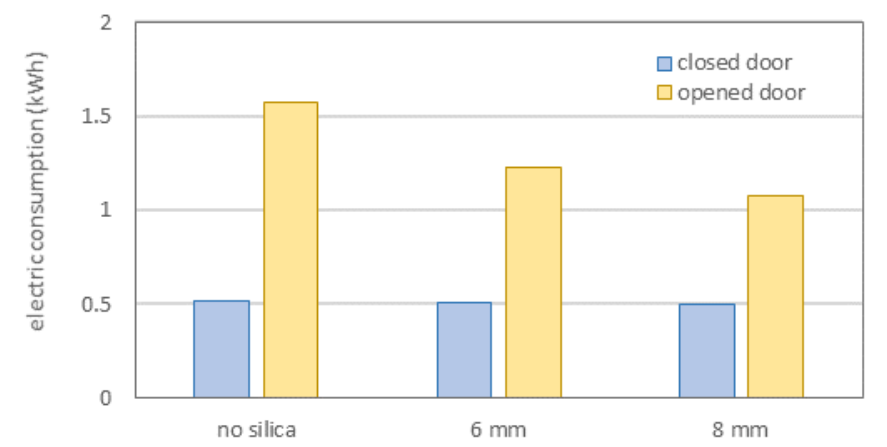

Fig. 7. The effect of silica gel on air flow rate returning and supplying in $\mathrm{AC}$

As in Garden by The Bay, the electricity consumption for the AC with silica gel is less. Figure 8 shows that the energy used to pump heat transfer from the air in the AC is less when the thick silica gel is used. For a closed-door experiment, the energy required is much less than for an opened-door experiment. When the door is opened, then fresh air will enter the evaporator. The fresh air is usually warmer than circulated air. Higher temperature entering the $\mathrm{AC}$ will make higher electricity consumption. The electricity consumption saving for inserting $8 \mathrm{~mm}$ silica gel is only $4 \%$ when the door is closed and $31 \%$ when the door is opened.

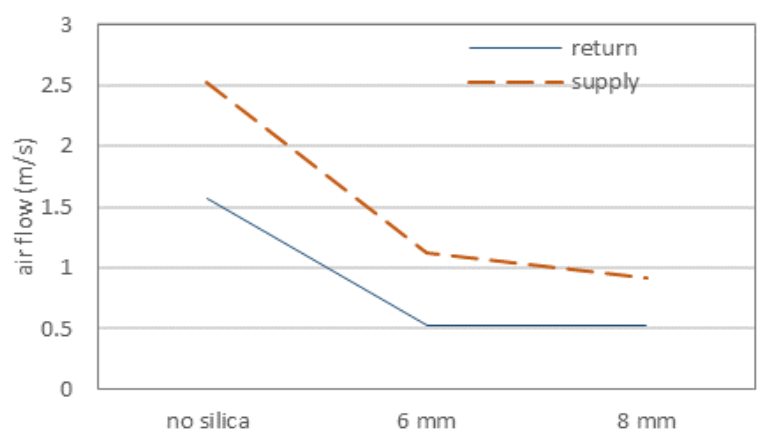

Fig. 8. Comparison of electricity consumption for $2 \mathrm{~h}$ experiment

The application of the result is that silica gel or other adsorbents can be inserted in fresh air grille before cooling coil of an Air Handling Unit (AHU) of a central air conditioning system. The silica gel or adsorbent will reduce the water vapor in the fresh air that is usually humid. Then, the air will transfer only sensible heat to the cooling coil. It will save electricity consumption for running the AC or AHU and chiller. Other suggestion is that the silica gel used combined with an absorption chiller [12]. When the air is humid and warm, silica gel can be used with an evaporative cooler (direct or indirect) to produce cool and dry air [11].

\section{Conclusion}

From the experiments conducted, the results are that the air humidity decreased and its temperature increased as it passed thru the silica gel either $6 \mathrm{~mm}$ or $8 \mathrm{~mm}$ thickness. The thicker the silica gel, the higher outlet air temperature from silica gel. This result was found during the experiment both when the door closed or opened. 
Silica gel reduces the condensate because some of the water vapor in the air is already absorbed before reach the cooling coil. Less condensate produced when the silica gel used is thicker.

Room temperature was the lowest when no silica gel used, and the RH was the lowest when $8 \mathrm{~mm}$ silica gel used before the cooling coil. The room temperature changes only $1.2 \%$ and $1.1 \%$ for having $6 \mathrm{~mm}$ and $8 \mathrm{~mm}$ silica gel during the opened-door experiment. Silica gel is suitable for reducing the humidity of outdoor air. The electricity consumption saving for inserting 8-mm silica gel is only $4 \%$ when the door is closed and $31 \%$ when the door is opened.

\section{References}

1. Ashrae, Fundamentals. [Online] from https://www.ashrae.org/technicalresources/ashrae-handbook/description-2017-ashrae-handbook-fundamentals (2017) p. 9.1-9.2. [Accessed on 19 July 2018].

2. Weatherspark, Average weather in Surabaya Indonesia. [Online] from https://weatherspark.com/y/124626/Average-Weather-in-Surabaya-Indonesia-YearRound (2018). [Accessed on 19 July 2018].

3. Atelier One, Gardens by the bay, Singapore. [Online] from http://www.atelierone.com/gardens-by-the-bay (2013). [Accessed on 19 July 2018].

4. H. Ferguson, Singapore's supertrees, Ingenia Issue 58. [Online] from https://www.ingenia.org.uk/Ingenia/Articles/aba20bc9-1bd4-4ff4-afb2-1820b6d838a4 (2014). [Accessed on 19 July 2018].

5. V. Mittal, B.K. Khan. Front. Energy Power Eng. China 2010, 4, 2, 161-165(2010). https://link.springer.com/article/10.1007/s11708-009-0070-5

6. A.T. Mohammad, S.B. Mat, M. Sulaiman, K. Sopian, A.A. Al-abidi. Energy and Buildings, 62,1-14 (2013). https://www.sciencedirect.com/science/article/pii/S0378778813001655

7. A. Gagliano, F. Patania, F. Nocera, A. Galesi. Thermal Science, 18,2: 563-576(2014). http://thermalscience.vinca.rs/pdfs/papers-2013/TSCI120526067G.pdf

8. D. Jani, M. Mishra and P. Sahoo. Applied Thermal Engineering, 104: 556-564(2016). https://www.sciencedirect.com/science/article/pii/S1359431116307724

9. G. Ding, X. Chen, Z. Huang, Y. Ji, Y. Li. Applied Thermal Engineering, 139,376-386 (2018). https://www.sciencedirect.com/science/article/pii/S1359431117360003

10. M. Khoukhi. International Journal of Materials, Mechanics and Manufacturing, 1,2:191-194 (2013). http://www.ijmmm.org/papers/041-TT313.pdf

11. M. Sultan, I.I. El-Sharkawy, T. Miyazaki, B.B. Saha, S. Koyama. Renewable and Sustainable Energy Reviews, 46,16-29(2015). https://www.sciencedirect.com/science/article/pii/S1364032115001264

12. D. La, Y. Dai, Y. Li, R. Wang, T. Ge. Renewable and Sustainable Energy Reviews, 14,130-147(2010). https://www.sciencedirect.com/science/article/pii/S1364032109001737 